\title{
Osteoarthicular diseases in the elderly: the challenge of rehabilitation
}

\author{
M locco \\ From de Senectute: Age and Health Forum \\ Catanzaro, Italy. 5-7 December 2009
}

During the third age, rehabilitative intervention has some particular characteristics, connected to, without any doubt, functional and biological characteristics, which are typical of this period of human life, and on the other side, connected to the common way to consider elderly people, by the elderly people themselves, by the caregivers and by the social community.

Too often pain, functional limitation, reduction of autonomy and of capacity to participate in life are considered normal, almost necessary, and accepted with resignation and without any opposition.

This common idea of the elderly person is in contrast with scientific literature data, which show only the request of a longer time in more young people to reach the goals and for their reintegration, without having serious cognitive deficits or important pathologies.

For this reason, fighting to change this negative common point of view about elderly age is a challenge belonging to "rehabilitation". Consequently it's important to improve the capacity of the elderly person (for example in a global vision like the bio-physical-social one proposed by ICF.

In a femur fracture, a hip replacement or a osseous synthesis surgery are less meaningful if they can't bring the patient to walk, to stand up, to sit down, to climb the stairs and take care of himself, like he did before his trauma. If the interdisciplinary work of the rehabilitation team is well done and appropriate (from the beginning soon after the trauma and the surgery), if it is constant and sufficiently protracted, it must and can warrant this result. Besides it must involve not only the elderly patient who does rehabilitation but also his family and the institutional environment that surrounds him.

"Rehabilitation" has another challenge: to improve physical and functional conditions of elderly people to

University Magna Graecia of Catanzaro, Italy limit the use of drugs and surgery interventions. We are talking about interventions on osteoarthritis patients, but especially regarding intervention for the reduction of changeable risk factors of falls, which are the most frequent cause of fracture and its negative complications, including death.

We have a double strategy: one is to intervene on the elderly population in general with AFA; the other one is to intervene on high risk elderly people through a specific work.

These kinds of interventions are normally collocated in the strict cooperation between hospital or university structures and local health service structures.

Published: 19 May 2010

doi:10.1186/1471-2318-10-S1-L65

Cite this article as: locco: Osteoarthicular diseases in the elderly: the challenge of rehabilitation. BMC Geriatrics 2010 10(Suppl 1):L65.

Submit your next manuscript to BioMed Central and take full advantage of:

- Convenient online submission

- Thorough peer review

- No space constraints or color figure charges

- Immediate publication on acceptance

- Inclusion in PubMed, CAS, Scopus and Google Scholar

- Research which is freely available for redistribution

Submit your manuscript at www.biomedcentral.com/submit 